\title{
THE EFFECT OF TWO DIFFERENT ADHESIVE SYSTEMS ON MICROLEAKAGE OF CLASS V COMPOSITE RESTORATION IN PRIMARY TEETH
}

\author{
Ahmed N. AbdAlnabi $B D s^{1}$, Azza Hanno $P h D^{2}$, Nadia A. Wahba $P h D^{3}$, \\ Seham A. Hanafy $P h D^{4}$
}

\begin{abstract}
INTRODUCTION: polymerization shrinkage of composite resins causes stresses that may exceed the strength of the bond with the surrounding tooth structure, leading to interfacial failure. The use of an adhesive system is always required.

OBJECTIVE: The purpose of this in vitro study was to compare the effect of total-etch adhesive system with self-etch adhesive system on microleakage of universal nano-hybrid composite resin when used to restore class $\mathrm{V}$ cavities in primary teeth.

MATERIALS AND METHODS: The sample consisted of 50 freshly extracted sound primary teeth. Standardized class V cavity preparations on the buccal surfaces were prepared and the sample was randomly divided into 2 equal groups:

Group I: 25 teeth received total etch adhesive system.

Group II: 25 teeth received self-etch adhesive system.

The cavities were restored with a universal nano-hybrid restorative material. All specimens were thermocycled and immersed in $0.5 \%$ basic fuchsine dye at $37 \mathrm{C}^{\circ}$ for 24 hours. Basic fuchsine penetration was assessed on a 4 point grading scale ( 0 to 4$)$ using a stereomicroscope to evaluate the microleakage of the restorations.

RESULTS: Comparing the percentage of microleakage scores of group I and group II at occlusal margin it was found that, the group I was significantly lower than group II ( $\mathrm{p}=0.041)$. As for percentage of microleakage scores for the gingival margin between groups I and II it was found that there was no significant difference $(\mathrm{p}=0.741)$. Comparing the percentage of microleakage scores at both the gingival and occlusal margis of group I and II, no significant difference was revealed $(\mathrm{p}=0.105)(\mathrm{p}=0.278)$ respectively. The sum of occlusal and gingival percentage of microleakage scores of group I compared to group II revealed no significant difference $(\mathrm{p}=0.325)$.

CONCLUSION: There is no significant difference in microleakage sum scores between total etch and self-etch adhesive system groups. At the occlusal margin, total-etch adhesive system was significantly better than the self-etch adhesive systems.

KEYWORDS: microleakage, total etch adhesive, self- etch adhesive, primary teeth.
\end{abstract}

1. B.D.S. Faculty of Dentistry Almergip University, Libya

2.Professor of Pediatric Dentistry and Dental Public Health

3.Professor of Pediatric Dentistry

4.Professor of Dental Biomaterial

\section{INTRODUCTION}

Microleakage is one of the most frequently encountered problems with composite restorations, especially at the gingival margins when located apical to the cementoenamel junction (CEJ). Marginal microleakage is an important causal factor in clinical failures of restorations (1).

Nanohybrids are resin based composites (RBCs), containing either a combination of nanofillers with nanoclusters or a combination of different types of filler particles. These RBCs have high filler loading, workable consistency, excellent polishability, as well as good handling, strength, and wear properties. However, due to extremely high surface area-to-volume ratio they require a higher degree of silanization than larger particulate fillers (2).

As a result of numerous advances in restorative composites, the use of an adhesive system is always required since composites themselves are not able to bond to dental tissues. Therefore, recent technology has led to the introduction of many adhesive systems to the market.

To avoid confusing and incorrect uses of the adhesives, Van Meerbeek et al (3-5), have proposed a classification according to different adhesion strategies and adhesives: the Etch and Rinse (ER) adhesive systems, the Self- Etch (SE) adhesive systems, and the glass ionomer adhesive systems.

The ER adhesives always involve the use of phosphoric acid, which permits demineralization of the dental tissues and, after rinsing, complete elimination of the smear layer. Therefore, in the course of the ER adhesion strategy, the adhesive resin (bonding) is applied in a different clinical step: the demineralization and the hybridization of dental substrate appear consecutively.

On the contrary, with the SE adhesives, the demineralization and the impregnation of the adhesive into the enamel-dentin support appear simultaneously. The demineralization process results from the acidic monomers, which are components of the adhesive system. Therefore, the SE adhesive must not be rinsed.

There are currently 4 different types of SE adhesives, which are indexed according to their $\mathrm{pH}$ value: the ultramild SE (pH about 2.5), the mild SE (pH about 2), the intermediary strong $\mathrm{SE}(\mathrm{pH}$ about 1.5$)$, and the strong SE $(\mathrm{pH}<1)(3-6)$.

On the enamel, for both ER and SE adhesive systems, bonding to the tissue are essentially micromechanical. On the dentin, for the ER adhesives, the mechanisms of 
adhesion are mainly micro-mechanical because the phosphoric acid is a very strong acid ( $\mathrm{pH}$ about 0.5 ). Phosphoric acid completely dissolves the mineral and so, the collagen fibers are totally exposed after etching. For the SE adhesives, the adhesion to the dentin is both micromechanical and chemical $(3,5)$.

The self-etch monomers are often less acidic than phosphoric acid and some minerals remain attached to the collagen fibers, permitting chemical links between dental substrate and functional groups of the adhesive monomers. Laboratory experiments have permitted comparison between different bonding materials and have pointed statistical differences between different adhesive systems $(7,8)$. The aim of this in vitro study was to compare the effect of self-etch adhesive system with total-etch adhesive system on microleakage of universal nano-hybrid composite resin when used to restore class $\mathrm{V}$ cavities in primary teeth.

\section{MATERIALS AND METHODS}

The approval of ethical committee was obtained before the commencement of study. The present study was an experimental laboratory comparative study. The study sample included fifty sound primary teeth, that were collected from outpatient clinic of Pediatric Dentistry Department Faculty of Dentistry Alexandria University. All teeth were cleaned from debris, blood stains and stored in distilled water at room temperature until usage. The sample size was based on a previous study assuming an effect size of 0.5 , alpha level of 0.05 and an $80 \%$ power. A minimum required sample size was calculated to be 25 for each of the 2 groups (9).

\section{Inclusion criteria}

- Freshly shed or extracted human primary teeth for orthodontic purpose.

- Sound teeth with no caries, enamel cracks, previous fillings.

\section{MATERIALS}

1. Carbide bur No.330. (Kerr, UK)

2. Universal nano-hybrid restorative material (Grandioß) (Voco Gmbh, Germany)

3. Etchant for acid-etch technique (contains phosphoric acid 35\%) (Vococid) (Voco Gmbh, Germany).

4. Light-curing one-component dentine and enamel bond (Solobond M) (Voco Gmbh, Germany).

5. Dual-curing self-etch-bond reinforced with nanofillers (futurabond ${ }^{\circledR}$ DC) (Voco Gmbh, Germany).

6. Light curing device (Ivoclar, Vivadent, Germany).

7. Stereomicroscope (Olympus stereomicroscope SZ11, Germany).

\section{METHODS}

All the teeth were examined using magnifying glass to assure that no crack lines were present. The exposed pulp chamber or root apices were sealed and covered with sticky wax. Each tooth was embedded in an acrylic block, with the buccal surface facing outwards. All selected teeth received standardized class $\mathrm{V}$ preparations (1.5-mm depth, 3-mm width, and (3) 2-mm height). The length of the bur was used as a guide for the cavity depth (10). They were then divided randomly into 2 equal groups.

Group I: Twenty five teeth were restored by total-etch adhesive system and composite resin.

Group II: Twenty five teeth were restored by self-etch adhesive system and composite resin.

\section{Storage and thermocycling}

All samples were labeled and stored in distilled water at $37^{\circ} \mathrm{C}$ inside an incubator unit for 24 hours before thermocycling. The specimens were subjected to thermocycling in water baths: 500 cycles between $5^{\circ} \mathrm{C}$ and $55^{\circ} \mathrm{C}$, with a dwell time of 15 seconds and a 15 -second transfer time between baths to simulate temperature fluctuations in the oral cavity (11).

\section{Microleakage test}

The exposed tooth surfaces were covered with three layers of nail polish except the surface of restoration and a surrounding $1 \mathrm{~mm}$ area, to prevent dye penetration. All specimens were immersed in $0.5 \%$ basic fuchsine dye at $37 \mathrm{C}^{\circ}$ for 24 hours. Teeth were removed from dye solution and washed under running water for half an hour. The teeth were sectioned buccolingually through the center of the restoration using a water-cooled diamond disc. The sectioning resulted in two approximately equal parts which were both analyzed for microleakage.

\section{Evaluation}

The cut surfaces of the sectioned teeth were examined and viewed under a stereomicroscope to analyze basic fuchsine penetration at the marginal seal of each restoration in occlusal and gingival directions. The samples were evaluated blindly by one examiner at the Dental Biomaterials Department. A 4 point grading scale (0 to 4 ) was used according to the scoring criteria (8.9). (Table 1)

Table (1): Microleakage scoring criteria.

\begin{tabular}{|r|l||}
\hline Score & Degree of microleakage \\
\hline Score 0 & No Microleakage \\
\hline Score 1 & Microleakage along the enamel \\
\hline Score 2 & $\begin{array}{l}\text { Microleakage extending beyond the amelodentintal } \\
\text { junction }\end{array}$ \\
\hline Score 3 & Microleakage along the floor of the cavity \\
\hline Score 4 & Microleakage reaching the pulp \\
\hline
\end{tabular}

\section{STATISTICAL ANALYSIS}

Statistical analysis was done using Statistical Package for Social Sciences (SPSS/ version 20) software. Yates corrected Chi- Square test was used to analyse the categorical data. $\mathrm{P}$ value was considered significant if $<$ 0.05 .

\section{RESULTS}

Comparing the percentage of microleakage scores of group I and group II at occlusal margin it was found that, the group I was significantly lower than group II $(\mathrm{p}=0.041)$. As for percentage of microleakage scores for the gingival margin between groups I and II it was found that there was no significant difference $(p=0.741)$. Comparing the percentage of microleakage scores at both the gingival and occlusal margins of group I and II, no significant difference was revealed $(p=0.105)(p=0.278)$ respectively. The sum of occlusal and gingival percentage of microleakage scores of group I compared to group II revealed no significant difference $(\mathrm{p}=0.325)$ (Table 2, Figs. $1-4)$. 
Table (2): Comparison of micoleakage scores between group I and II at the occlusal and gingival margin of the restoration.

\begin{tabular}{|c|c|c|c|c|c|c|c|c|}
\hline \multirow{3}{*}{$\begin{array}{c}\text { Microleakage } \\
\text { score }\end{array}$} & \multicolumn{4}{|c|}{ Group I total etch } & \multicolumn{4}{|c|}{ Group II Self etch } \\
\hline & \multicolumn{2}{|c|}{ Occlusal margin } & \multicolumn{2}{|c|}{ Gingival margin } & \multicolumn{2}{|c|}{ Occlusal margin } & \multicolumn{2}{|c|}{ Gingival margin } \\
\hline & No. 25 & $\%$ & No.25 & $\%$ & No.25 & $\%$ & No.25 & $\%$ \\
\hline 0 & 18 & 72.0 & 12 & 48.0 & 11 & 44.0 & 10 & 40.0 \\
\hline 1 & 6 & 24.0 & 7 & 28.0 & 12 & 48.0 & 8 & 32.0 \\
\hline 2 & 1 & 4.0 & 6 & 24.0 & 2 & 8.0 & 6 & 24.0 \\
\hline 3 & 0 & 0.0 & 0 & 0.0 & 0 & 0.0 & 1 & 4.0 \\
\hline 4 & 0 & 0.0 & 0 & 0.0 & 0 & 0.0 & 0 & 0.0 \\
\hline P1 & \multicolumn{4}{|c|}{0.105} & \multicolumn{4}{|c|}{0.278} \\
\hline $\mathrm{P} 2$ & \multicolumn{8}{|c|}{0.741} \\
\hline P3 & \multicolumn{8}{|c|}{0.041} \\
\hline P4 & \multicolumn{8}{|c|}{0.325} \\
\hline
\end{tabular}

P1 comparison between gingival margins and occlusal margins in the same group.

$\mathrm{P} 2$ comparison between gingival margins in the two groups

P3 comparison between occlusal margins in the two groups.

P4 comparison between total scores of group I and II.

40

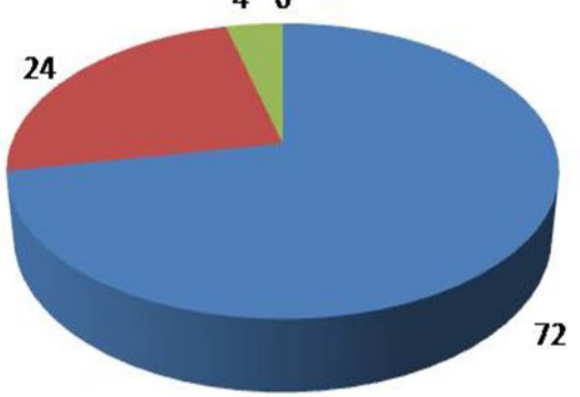

Group I total-etch occlusal

Figure 1: Microleakage scores at the occlusal margin for group I.

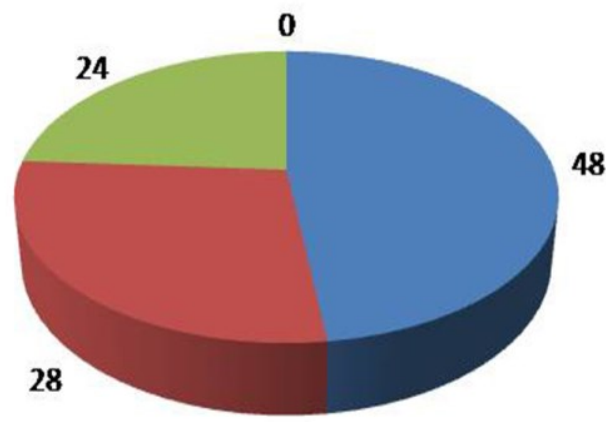

Group I total-etch gingival

Figure 2: Microleakage scores at the gingival margin for group I.

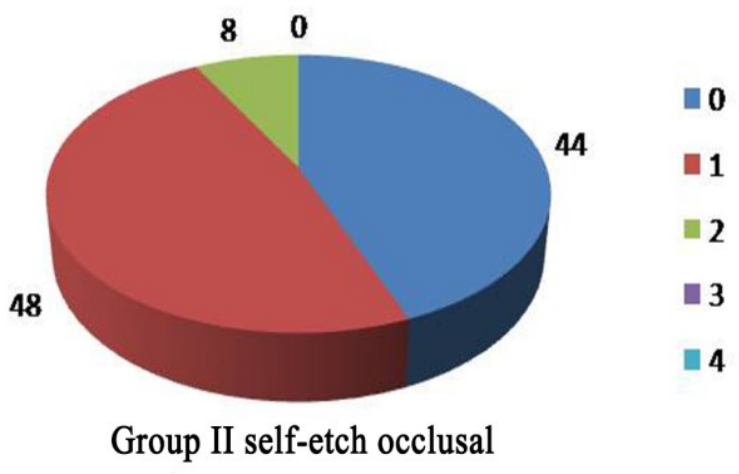

Figure 3: Microleakage scores at the occlusal margin for group II.

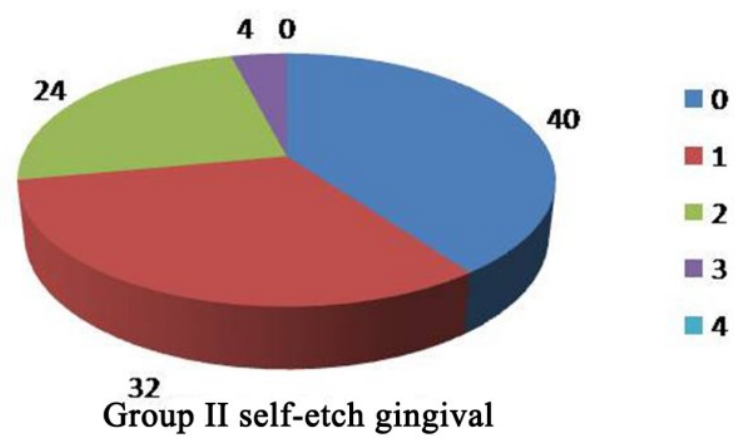

Figure 4: Microleakage scores at the gingival margin for group II. 


\section{DISSCUSION}

Marginal seal plays a major role in the success of dental restorations. Additionally, proper adhesion between the restorative material and the cavity walls results in good marginal sealing with less microleakage and a longer life of the restoration (12).

Natural sound primary molars extracted for orthodontic purpose or near their time of shedding were selected to ensure standardization and that any microleakage that would take place could only be attributed to the restoration used. For this reasons, standardization of cavity size, shape and depth, in addition to material application and polymerization was adopted. The only variable was the adhesive tested.

After fulfilling the inclusion criteria, teeth were randomly distributed to two groups I and II. Randomization was adopted to ensure that on average all factors influencing the study outcome are equal between the two studied groups,

Class V lesions present special problems with any restorative material, because the selected material is required to bond to enamel and dentin/cementum. Dentin and cementum are less favorable substrates for bonding (13).

In the present study standardization of cavity dimensions, was achieved by the cavity outline form through a preformed outline cut in an orthodontic band material that was placed around the tooth.

The universal nano-hybrid restorative material that was used in this study has higher filler loading $(87 \% \mathrm{w} / \mathrm{w}$ inorganic fillers) compared to conventional resin composite and average filler particle size is 20-60 $\mathrm{nm}$ (14).

In group I the adhesive system used is a light curing one component etch-and-rinse. Whereas in group II the adhesive system is dual-curing self-etch-bond, as dualcured adhesive systems polymerize via both light and chemical reactions. It has been stated that these systems have better and more complete polymerization. The $\mathrm{pH}$ of Future bond ${ }^{\circledR}$ DC used in this study is 1.5 ; hence, it falls in the category of intermediary strong self-etching adhesive $(8,15)$.

In order to simulate the oral condition all specimens were subjected to thermocycling at 500 cycles between $5^{\circ} \mathrm{C}$ and $55^{\circ} \mathrm{C}$, with a dwell time of 15 seconds and a 15 second transfer time between baths to simulate temperature fluctuations in the oral cavity. The use of thermocycling highlights the mismatch in the thermal coefficient of expansion between the restoration and tooth structure, which would result in repeated expansioncontraction stresses at the tooth-restoration interface leading to gap formation and microlrakage (16).

In the present study, the microleakage was detected with the dye penetration which was evident within the crack lines, suggesting the severity of the loss of integrity. This observation is in accordance with Mehmet Dalli et al (17) who conducted a comparative assessment of in vitro microleakage of five different new generation self-etching adhesive systems.

Our study finding showed that, higher microleakage scores were detected for the self-etching adhesive group at the occlusal margin than etch and rinse adhesive group. This finding is in agreement with Sensi et al. $(18,19)$. On the contrary, Santini et al. (20) revealed no significant difference between self-etching adhesive systems and etch and rinse adhesive systems in the degree of microleakage in Class V cavities.

The statistical analysis in this present study indicated that, a higher amount of leakage at the gingival margin compared to occlusal margin was found in both groups, however, the differences were not significant. This finding is in agreement with the study conducted by Bracket et al. (21). The investigators used different combinations of bonding agents and resin composite in class $\mathrm{V}$ resin restorations. The study proved that no material could eliminate microleakage at the gingival margin.

The results of the present study could be attributed to the fact enamel thickness is lesser in the gingival margin compared to the occlusal margin. In this context, if microleakage is deemed to take place, the dye will have to travel a short distance until it reaches dentin, which will accordingly affect the scoring rendering higher score at the gingival aspect (22). Moreover, bonding to dentin presents a much greater challenge, as it contains a substantial proportion of water and organic materials, which presents a moist surface that impairs the bonding mechanism.

When comparing group I and II (both gingivaly and occulsally), the results showed no significant differences between groups. This finding is in agreement with the study of Sánchez et al. (23). Moreover, El Sayed et al. (24) concluded that although all adhesive systems exhibited dye penetration at both occlusal and gingival margins, etch and rinse systems are still considered a gold standard for adhesion.

The results of the present study substantiate the belief that the search for an ideal material that would fulfill all requisites of perfect adhesion, strength and aesthetics should never cease.

\section{CONCLUSIONS}

1- At the occlusal margin, total-etch adhesive system was significantly better than the self-etch adhesive systems

2- At the gingival margin, no difference was found in both groups.

3- The percentage of microleakage scores at the occlusal and gingival margins within each group showed comparable values.

4- The combined sum of percentage microleakage scores at the gingival and occlusal margins was comparable in both groups.

\section{RECOMMENDATIONS}

Further clinical studies using different adhesive systems are still needed in search of a material to completely eliminate microleakage.

\section{CONFLICT OF INTEREST}

The authors declare that they have no conflict of interests.

\section{REFERENCES}

1. Ahmed WM. Gingival Microleakage of Class V Resin Composite Restorations with Fiber Inserts. 2012. University of Toronto.

2. Ilie N, Hickel R. Macro-, micro- and nanomechanical

on 
siloraneandmethacrylate-based composites. Dent Mater 2009; 25: 810-9.

3. Van Meerbeek B, Vargas M, Inoue S, Yoshida Y, Peumans M, Lambrechts $\mathrm{P}$, et al. Adhesives and cements to promote preservation dentistry. Oper Dent 2001; (Suppl 6): 119-44.

4. Van Meerbeek B, De Munck J, Yoshida Y, Inoue S, Vargas M, Vijay $\mathrm{P}$, et al. Buonocore Memorial Lecture adhesion to enamel and dentin: current status and future challenges. Oper Dent 2003; 28: 215-35.

5. Van Meerbeek B, Peumans M, Poitevin A, Mine A, Van Ende A, Neves A, et al. Relationship between bond-strength tests and clinical outcomes. Dent Mater 2010; 26: e100-e21.

6. Van Meerbeek B, Yoshihara K, Yoshida Y, Mine A, De Munck J, Van Landuyt KL. State of the art of self-etch adhesives. Dent Mater 2011; 27: 17-28.

7. Bradna P, Vrbova R, Dudek M, Roubickova A, Housova D. Comparison of bonding performance of self-etching and etch \& rinse adhesives on human dentin using reliability analysis. J Adhes Dent 2008; 10: 423-9.

8. Vargas MA, Swift EJ. Microleakage of resin composite with wet versus dry bonding. Am J Dent 1994; 7: 187-9.

9. Tomczak M, Tomczak E, Kleka P, Lew R. Using power analysis to estimate appropriate sample size. TRENDS in Sport Sciences 2014; 4: 195-206.

10. Ahmadi R. In vitro comparison of microleakage of nanofilled and flowable composite in restoring class $\mathrm{V}$ cavity in primary teeth. Zahedan $\mathrm{J}$ Res Med Sci 2013; 15: 45-50.

11. Gale MS, Darvel BW. Thermal cycling procedures for laboratory testing of dental restorations. J Dent 1999; 27: 89-99.

12. Taylor MJ, Lynch E. Review microleakage. J Dent 1992; 20: 3-10.

13. Hegde MN, Vyapaka P, Shetty S. A comparative evaluation of microleakage of three different newer direct composite resins using a self-etching primer in class V cavities: An in vitro. J Conserv Dent 2009; 12: $160-3$.

14. Al-Razooki AA, UR Rehman MM. Microleakage in Class V nanofilled composite compared with traditional hybrid and flowable composite restorations: An in vitro study. Pak Oral Dental J 2010; 30: 215-19.

15. Arrais CA, Giannini M, Rueggeberg FA. Effect of sodium sulfinate salts on the polymerization characteristics of dual-cured resin cement systems exposed to attenuated light-activation. J Dent 2009; 37: 219-27.

16. Gale MS, Darvel BW. Thermal cycling procedures for laboratory testing of dental restorations. J Dent 1999; 27: 89-99.

17. Mehmet D, Fatma A, Emrullah B, Bayram I, Cafer S, Hakan Ç, et al. A comparison of the levels of microleakage of five adhesive. J Res Dent 2013; 1: 66-71.

18. Sensi LG, Lopes GC, Monteiro S Jr, Baratieri LN, Vieira LC. Dentin bond strength of self-etching primers adhesives. Oper Dent 2005; 30: 63-8.
19. Abo T, Uno S, Sano H. Comparison of bonding efficacy of an all-in-one adhesive with a self-etching primer system. Eur J Oral Sci 2004; 112: 286-92.

20. Santini A, Ivanovic V, Ibbetson R, Milia E. Influence of marginal bevels on microleakage around Class $\mathrm{V}$ cavities bonded with seven self-etching agents Am J Dent 2004; 17: 257-61.

21. Bracket WW, Haisch LD, Pearce MG, Brackett MG. Microleakage of Class $\mathrm{V}$ resin composite restorations placed with self-etching adhesives. J Prosthet Dent 2004; 91: 42-5.

22. Tay FR, Suh BI, Pashley DH, Prati C. Chuang SF, Li F. Factors contrib-uting to the incompatibility between simplified-step adhesives and self-cured or dual-cured composites. Part II, Single-bottle, Totaletch adhesive. J Adhes Dent 2003; 5: 91-105.

23. Sánchez-Ayala A, Farias-Neto A, Vilanova LSR, Gomes JC, Gomes OMM. Marginal microleakage of class $\mathrm{V}$ resin based Composite restorations bonded with six one-step self-etch systems. Braz Oral Res 2013; 27: 225-30.

24. El Sayed HY, Abdalla AI, Shalby ME. Marginal microleakage of composite resin restorations bonded by desensitizing one step self-etch adhesive. Tanta Dent J 2014; 11: 180-8. 